\title{
DYNAMIC EFFECTS OF DROUGHT ON U.S. CROP AND LIVESTOCK SECTORS
}

\author{
AMANDA M. LEISTER* \\ Department of Agricultural and Resource Economics, Colorado State University, Fort Collins, CO \\ PHILIP L. PAARLBERG \\ Department of Agricultural Economics, Purdue University, West Lafayette, IN \\ JOHN G. LEE \\ Department of Agricultural Economics, Purdue University, West Lafayette, IN
}

\begin{abstract}
This study investigates the long-term adjustments to drought by crop and livestock sectors using a dynamic partial equilibrium quarterly model of the U.S. agricultural economy. Results show that short-term drought effects including increases in crop and forage prices are in tandem with decreased live cattle prices resulting from drought-induced beef cattle herd liquidation. Crop price increases in the long run cause livestock inventory reductions, leading to fewer animals moving through the U.S. meat supply chain and increased livestock prices. Longer-term market adjustments cause a significant decrease in consumer surplus, and prolonged drought amplifies and extends the model-predicted results.
\end{abstract}

Keywords. Crops, drought, dynamic model, economics, livestock

JEL Classifications. Q10, Q15, Q19

\section{Introduction}

Drought has been a severe challenge faced by many crop and livestock producers in the United States in 2011 and 2012. Nearly 80\% of U.S. agricultural land experienced drought conditions during the summer of 2012, the effects of which exacerbated the initial drought impacts of 2011 and are expected to be felt for years to come (Wallander et al., 2013). Several studies show significant short-run economic losses from the 2011 or 2012 drought including an annual national study by Anderson, Welch, and Robinson (2012) and regional analyses by Bauman et al. (2013), Guidry and Pruitt (2012), and Watkins (2012). Dhoubhadel, Azzam, and Stockton (2015) provide an analysis of the 2012 U.S. drought by implementing supply shocks to crop sectors in an equilibrium displacement model to understand the potential effects of waiving the U.S.

The authors thank two anonymous reviewers and Krishna Paudel, co-editor of JAAE, for their helpful comments regarding this article.

*Email: amanda.leister@colostate.edu 
Environmental Protection Agency's Renewable Fuel Standard (RFS) mandate on livestock and crop sectors. The authors then assess how supply shocks in the crop sector in 2012 affect feed commodity prices, with specific attention to corn prices, as well as how the availability of pasture for livestock grazing affects livestock production. This valuable contribution to the literature sheds light on how changes to RFS mandates could affect livestock and crop sectors in the presence of drought.

Livestock market adjustments to exogenous shocks such as macroeconomic shocks, drought shocks, or livestock disease evolve over time and require proper accounting of the dynamic adjustment process (Dorfman and Lastrapes, 1996; Gramig and Horan, 2011), which is lacking in the current literature regarding drought impacts on the U.S. livestock sector. Our work furthers the analysis of U.S. drought impacts in three critical ways. First, we employ a dynamic integrated agricultural model to provide quarterly estimates of drought impacts over an 8 -year period of analysis. Second, we use observed data to implement supply shocks over eight quarters for drought in the United States that were experienced from 2011 through 2012. Third, our work provides the essential inclusion of the drought shocks that affected both crop yields and livestock production. There is evidence of drought-induced culling of livestock in both 2011 and 2012 that resulted from the immediate changes in pasture and forage availability and increases in feed costs. Although Dhoubhadel, Azzam, and Stockton (2015) implement yield shocks to crop supplies, which affect feed costs in the livestock sector, the drought-induced culling that took place is not accounted for in their work. This research provides an analysis of the effects of observed drought on the U.S. agricultural economy in a dynamic, integrated agricultural model that accounts for both yield shocks and drought-induced culling over eight quarters in 2011 and 2012.

Although drought-related shocks cause decreased supplies in livestock and crop sectors, the resulting price impacts may mitigate the negative effects on production. Ding, Hayes, and Widhalm (2011) state that agricultural sector impacts at the national level could be positive if commodity prices increase by a higher percentage relative to supply decreases. Accordingly, this work recognizes that there are winners and losers both by production sector and within each agricultural sector and investigates how crop and livestock producers in the United States have been, and will continue to be, affected by prolonged drought. Although regional droughts can have severe economic impacts on producers in areas that are directly affected, this study assesses the total national effects of the 2011 and 2012 drought, as well as the extent to which an extended drought could affect the U.S. agricultural economy.

The importance of understanding the impacts of drought is evident. Work to examine a variety of economic factors related to drought include studies that assess how poor producers and consumers in developing countries are affected by drought and extreme weather events (Julca, 2012; Kusunose and Lybbert, 2014; 
Lawson and Kasirye, 2013; Mwakaje, 2013; Verner and Breisinger, 2013), work that examines the links between drought and conflict in poor regions (Jia, 2014; Maystadt and Ecker, 2014), as well as analysis of how crop yields are impacted by drought (Boubacar, 2012; Westcott and Jewison, 2013). The research regarding the economic implications of drought provides a rich literature on the topic. This work sheds further light on the impacts of drought with a specific focus on anticipated producer and consumer welfare effects resulting from observed changes in crop yields and drought-induced culling of livestock by employing a framework that integrates the U.S. agricultural economy. To accomplish this, our study will proceed as follows. First, we describe the integrated agricultural model and key parameters that drive results. Next, the drought-related shocks that we calculate for livestock and crop sectors are discussed. The subsequent results section includes the price and welfare impacts of drought as well as potential effects of continued drought. Finally, we provide the key conclusions of this work.

\section{The Integrated Agricultural Model}

The framework used in this analysis is a dynamic partial equilibrium model that determines changes in prices and quantities relative to baseline values for U.S. livestock products, livestock, and crops in response to production shocks from drought conditions. The model baseline includes quarterly values calculated from the annual U.S. Department of Agriculture (USDA) baseline using seasonal adjustment factors. U.S. agricultural sectors are modeled by crops and forage and pasture sectors that are used as inputs by animal agriculture sectors that are vertically linked to animal processing sectors and, ultimately, demand for final goods. The seven input sectors for animal agriculture include wheat, coarse grains, rice, soybeans, soybean meal, soybean oil, and forage and pasture. The six animal agriculture sectors include cattle, hogs, birds, lamb and sheep, eggs, and dairy. Animal processing comprises four sectors including beef and cattle, pork and hogs, lamb and sheep meat, and poultry meat and birds. The final goods available for consumption include beef, pork, poultry meat, lamb and sheep meat, dairy products, eggs, rice, coarse grains, wheat, and soybean oil (Paarlberg et al., 2008).

Paarlberg et al. (2008) used this framework in tandem with an epidemiological model to assess the impacts of foreign animal disease on U.S. livestock sectors. Accordingly, the authors investigated the effects of a hypothetical outbreak of foot-and-mouth disease (FMD) by integrating results for livestock production impacts from an epidemiological model into the economic model that we use for this research. Although Paarlberg et al. invoke disease-related production shocks to livestock sectors and account for FMD-related trade embargoes in the economic model, our work employs historically observed drought-induced production and yield shocks to both crop and livestock sectors in the economic 
model alone. As our work does not consider disease impacts, we refrain from using an epidemiological model. This integrated agricultural model is ideal for the study of drought impacts because it allows for the dynamic analysis of the effects of drought-induced supply shocks to crops and livestock sectors over an 8 -year time horizon.

Although work on the economy-wide effects of drought in Australia has employed computable general equilibrium (CGE) modeling frameworks (Banerjee et al., 2013; Horridge, Madden, and Wittwer, 2005), we find that this detailed partial equilibrium model for the U.S. agricultural economy is best suited for our analysis. This framework allows for the detailed accounting of the intricacies of the agricultural supply chain that is not permissible given the simplifying assumptions that are necessary in CGE frameworks with more highly aggregated agricultural sectors. Furthermore, CGE frameworks that are annual in nature do not account for the seasonality that occurs for crop production by sector, which we are able to include given our quarterly modeling framework. The economic model we employ has the structure of a specific-factors model with perfect competition. This framework is based on key assumptions for economic agents and economic activity. Producers and consumers are assumed to be price takers that maximize well-defined objective functions. Consumers maximize a well-defined, homothetic utility function, given income and prices, which results in a set of per capita demand functions for final goods. According to Paarlberg et al. (2008), per capita consumption of final goods in quarter $t$ is defined as $\mathbf{D P}_{t}$. Final goods are beef, pork, poultry meat, lamb meat, eggs, milk, wheat, coarse grains, rice, and soybean oil. Per capita demand functions defined by the vector $\mathbf{D P}_{t}$ depend on a vector of prices for final goods, $\mathbf{P R}_{t}$, and per capita income, $y_{t}$ :

$$
\mathrm{DP}_{t}=\mathrm{DP}_{t}\left(\mathbf{P R}_{t}, y_{t}\right)
$$

Total U.S. consumption in quarter $t$ depends on per capita consumption multiplied by population at time $t, \mathbf{p o p}_{t} . \mathrm{DF}_{t}$ is the vector of total consumption of final goods:

$$
\mathrm{DF}_{t}=\operatorname{pop}_{t} * \mathrm{DP}_{t}
$$

Producers maximize profit given a well-defined, constant-returns-to-scale production function. The model includes four factors of production for each sector including mobile factors, sector-specific intermediate goods, sector-specific primary factors, and land that is used for crop production and pasture for livestock use. The model vertically links farm prices for crops and livestock; wholesale prices for meats, milk, and eggs; and retail prices for all final goods by calculated marketing margins. The model is solved in Microsoft Excel by satisfying market-clearing conditions for prices and quantities.

Meats, milk, and eggs represent separate production sectors, with zero-profit conditions holding for each, with production occurring at time $t$. Factors are 
in perfectly elastic supply with exogenous prices described by a column vector, $\mathbf{W}_{t}$. The vector $\mathbf{P} \mathbf{A}_{t}$ describes the prices for animal intermediate inputs, and $\mathbf{R}_{t}$ denotes prices for sector-specific primary factors. Unit cost given constant returns to scale is only a function of factor prices, $\mathbf{C M}\left(\mathbf{W}_{t}, \mathbf{P A}_{t}, \mathbf{R}_{t}\right)$. Wholesale prices of meats, milk, and eggs at time $t$ are described by $\mathbf{P M}_{t}$. Constant returns to scale and perfect competition lead to the following zero-profit conditions:

$$
\mathbf{C M}\left(\mathbf{W}_{t}, \mathbf{P A}_{t}, \mathbf{R}_{t}\right)=\mathbf{P M}_{t} \text {. }
$$

The production of meats, milk, and eggs is determined by factor-market-clearing conditions. AM is the matrix of per unit demands for factors of production for meats, milk, and eggs, and $\mathbf{Q M}_{t}$ is the column vector of meats, milk, and eggs outputs at time $t$. The column vector $\mathbf{Z}$ consists of a partition $\left[\mathbf{K}_{t}, \mathbf{D A}_{t}\right]^{T}$, where $\mathbf{K}_{t}$ indicates primary, sector-specific factors in fixed supply and $\mathbf{D A} \mathbf{A}_{t}$ indicates the derived demands for animals at time $t$. Therefore, AM only depends on factor prices, given the following factor-market-clearing conditions:

$$
\mathbf{A M}\left(\mathbf{W}_{t}, \mathbf{P A}_{t}, \mathbf{R}_{t}\right) \times \mathbf{Q} \mathbf{M}_{t}=\mathbf{Z}
$$

The sector-specific factors and derived demands for animals create the vertical linkages to animal agriculture, final products, as well as linkages for derived demand for feedstuff, crops, and the factors of production used in the crop sector. Because each type of animal has unique features, the model explicitly accounts for each type as described in detail in the appendix of Paarlberg et al. (2008).

Livestock are intermediate inputs into meat production. The model explicitly tracks livestock going through the production system over time. Cattle, sheep, and hogs have production cycles that span longer than one quarter. Changes in breeding and replacement inventories are determined by changes in salvage values and the expected relative profitability of producing animals or products for future sale. For example, cow inventories adjust endogenously to changes in input prices and expected returns. Cow/calf producers are assumed to form expectations for future returns based on the returns in the previous quarter. Declines in live cattle prices combined with rising feed costs causes cow/calf operators to reduce breeding cow inventories, which in turn results in fewer calves and market cattle for slaughter several quarters later as cattle move through the production cycle. Wheat, coarse grains, soybean meal, and forage and pasture are available for feedstocks for each livestock type and corresponding growth stage. This feature creates unique derived input demands for feedstocks (Paarlberg et al., 2008).

Livestock and crop production adjust across time based on biological limitations. Crop production by type occurs at set times of the year and then becomes carry-in stock in subsequent quarters until a new crop is harvested. Acreage allocations for future crops are set in the January-March quarter of each year based on expected returns for each crop at harvest, which are equal to the previous harvest prices plus any government payments. For winter crops, 
such as winter wheat, this means that the area for planting in the next fall is determined by the cropping decisions in the first quarter of the year. Rice is harvested in the third quarter, and soybeans are assumed to be harvested in the fourth quarter. Coarse grains are harvested in quarters 3 and 4 . Forage and pasture production occurs in quarters 2 and 3 .

The vector of expected crop returns calculated in the first quarter, $\mathbf{P}_{1}^{\mathrm{e}}$, given the assumption of zero-profits, determines crop production for quarter $t$ (Paarlberg et al., 2008):

$$
\mathrm{C}_{t}\left(\mathbf{W}, \mathbf{R}^{\mathrm{e}}, \boldsymbol{\tau}\right)=\mathbf{P}_{1}^{\mathrm{e}}
$$

where $\mathbf{R}^{\mathrm{e}}$ is the vector of expected returns to capital that is calculated by the zero-profit condition, $\boldsymbol{\tau}$ is the return to land, and $\mathbf{W}$ is exogenous, given the perfectly elastic supply of the mobile input.

Crop output for quarter $t$ is determined by sector-specific, factor-marketclearing conditions, given expected rent and factor prices in quarter 1 :

$$
\mathbf{a}_{\mathrm{K}}\left(\mathbf{W}, \mathbf{R}^{\mathrm{e}}, \boldsymbol{\tau}\right) \times \mathbf{Q}_{t}=\mathbf{K}_{1} .
$$

The return to land, which is mobile among crops, is determined in the first quarter by the demand and supply for land for the upcoming crops in period $t$ :

$$
\mathbf{a}_{t}\left(\mathbf{W}, \mathbf{R}^{\mathrm{e}}, \boldsymbol{\tau}\right) \times \mathbf{Q}_{t}=\mathrm{T},
$$

where $T$ is total land available for crops in $t$.

Expected returns to sector-specific factors determine crop output, yet actual returns to the sector-specific factors, $\mathbf{R}_{t}$, can differ from expected returns. The market-clearing identities determine actual market prices, $\mathbf{P m}_{t}$. When the market prices of crops are determined, government payments (including loan deficiency payments and countercyclical payments) are calculated for the crop produced at time $t$, which holds for $85 \%$ of crops enrolled in traditional government programs. The actual return to the program crop, $\mathbf{P}_{t}$, is determined by including government payments:

$$
\begin{gathered}
\mathbf{P}_{t}=\mathbf{P m}_{t}+0.85 \times \mathbf{D P} \times(\mathbf{y} \times \mathbf{A}) / \mathbf{Q}+\mathbf{Z}_{1}+\mathbf{Z}_{2}, \\
\text { where } \mathbf{Z}_{1}=\left\{\begin{array}{l}
0.85 * \frac{\left(\mathbf{T P}_{t}-\mathbf{P m}_{t}\right)(\mathbf{y} * \mathbf{A})}{\mathbf{Q}}, \text { if } \mathbf{P m}_{t}<\mathbf{T P}_{t}, \\
0, \text { if } \mathbf{P m}_{t}>\mathbf{T P}_{t}
\end{array}\right. \\
\mathbf{Z}_{2}=\left\{\begin{array}{l}
\left(\mathbf{L R}_{t}-\mathbf{P m}_{t}\right) \text { if } \mathbf{P m}_{t}<\mathbf{L R}_{t} \\
0, \text { if } \mathbf{P m}_{t}>\mathbf{T P}_{t}
\end{array}\right.
\end{gathered}
$$

where $\mathbf{y}$ is a vector of program yields defined by the U.S. government, $\mathbf{A}$ is a vector of base acreages, and $\mathrm{Q}$ is a vector of quarterly production. In addition, approximately $15 \%$ of crops were covered under the Average Crop Revenue 
Election program with payments calculated using a moving average of crop prices and yields. Finally, there is no government program for forage and pasture. Therefore, the market price is the return to forage and pasture. Accordingly, the actual return to physical and human capital in period $t, \mathbf{R}_{t}$, is determined by the zero-profit condition:

$$
\mathbf{C}\left(\mathbf{W}, \mathbf{R}_{t}, \boldsymbol{\tau}\right)=\mathbf{P}_{t}
$$

\section{Parameters}

We use the logarithmic differential version of the integrated agricultural sector model, which is driven by a suite of parameters. The three sets of parameters that drive the model include livestock feed-balance calculators, the revenue shares for all industries, and elasticities, which are based on estimates in the literature. The livestock-feed balance calculators link the stocks and flow of animals to available feed supplies throughout the supply chain. Each animal species has specific feed demands (rations) at each production stage and corresponding typical weight gain during each production phase. Unique rations composed of feed grains, wheat, soybean meal, and forage and pasture are determined by species and production phase. The average weight gain for each phase of production determines total feed consumption for a given phase, and average daily weight gain determines the length of time each species remains in a given production phase. The time from birth to market age is then calculated according to the total amount of time spent in each production phase to reach the finished, market stage for each animal species.

Revenue and factor shares are determined by sector. Cost-of-production data for corn, wheat, soybeans, rice, hogs, cattle, and milk are divided by production revenue to calculate the respective revenue shares. Government payments are included as revenue for relevant crop sectors. Overall, crops have relatively even allocations among exogenous inputs, land, and the residual cost of capital and management. The major revenue share for live animals is feed costs, followed by the residual return to capital and management. Meat industries show relatively low returns to capital and management because the majority of revenue is allocated to animal costs. Exceptions exist for meat, eggs, and poultry, as detailed by Paarlberg et al. (2008). Revenue shares for individual feed ingredients result from the livestock-feed balances, which calculate feed use on a per animal basis by species and production phase.

Elasticities employed in the model and are grouped into several sets, all of which can be found in the appendix of Paarlberg et al. (2008), with the exception of own-price elasticity estimates for meats. The own- and cross-price elasticities of retail demand are based on estimates from econometric models in the literature or estimated by Paarlberg et al. (2008) and are listed in Table 1. The crossprice effects are nonnegative, which implies that commodities in the model are 
Table 1. Price Elasticities for Final Goods

\begin{tabular}{|c|c|c|c|c|c|c|c|c|c|c|}
\hline & Beef & Pork & Poultry & Lamb & $\begin{array}{l}\text { Coarse } \\
\text { Grain }\end{array}$ & Wheat & Rice & Milk & $\begin{array}{l}\text { Soybean } \\
\text { Oil }\end{array}$ & Eggs \\
\hline Beef & -0.808 & -0.005 & -0.01 & 0 & 0 & 0 & 0 & 0 & 0 & 0 \\
\hline Pork & 0.01 & -0.856 & -0.024 & 0 & 0 & 0 & 0 & 0 & 0 & 0 \\
\hline Poultry & 0.048 & -0.039 & -0.707 & 0 & 0 & 0 & 0 & 0 & 0 & 0 \\
\hline Lamb & 0 & 0 & 0 & -0.4 & 0 & 0 & 0 & 0 & 0 & 0 \\
\hline $\begin{array}{c}\text { Coarse } \\
\text { grain }\end{array}$ & 0 & 0 & 0 & 0 & -0.3 & 0 & 0 & 0 & 0 & 0 \\
\hline Wheat & 0 & 0 & 0 & 0 & 0 & -0.309 & 0.036 & 0 & 0 & 0 \\
\hline Rice & 0 & 0 & 0 & 0 & 0 & 0.229 & -0.328 & 0 & 0 & 0 \\
\hline Milk & 0 & 0 & 0 & 0 & 0 & 0 & 0 & -0.397 & 0 & 0 \\
\hline $\begin{array}{c}\text { Soybean } \\
\text { oil }\end{array}$ & 0 & 0 & 0 & 0 & 0 & 0 & 0 & 0 & -0.314 & 0 \\
\hline Eggs & 0 & 0 & 0 & 0 & 0 & 0 & 0 & 0 & 0 & -0.1103 \\
\hline
\end{tabular}

Source: Paarlberg et al. (2008).

substitutes. The own-price elasticities for meats used in this analysis are inelastic, which is consistent with the literature on meat demand elasticity estimates (Eales and Unnevehr, 1988; Seale et al., 2003; Tonsor, Mintert, and Schroeder, 2009; USDA-ERS, 2012), yet differs from the elastic meat demand that is assumed in Paarlberg et al. (2008). Elasticities range from -0.4 for lamb meat to -0.9 for pork. Pork is the most price sensitive meat, whereas poultry $(-0.7)$ is less sensitive to price changes than pork or beef $(-0.8)$, as is consistent in studies of U.S. meat demand (Brester and Schroeder, 1995; Tonsor and Marsh, 2007). Derived demand behaviors that determine commodity outputs are affected by substitution elasticities. The substitution elasticities for meat and feed use, along with their estimations, are detailed in Paarlberg et al. (2008) and are consistent with the literature. The substitution elasticities govern the ability to substitute feeds in response to price changes. In most instances, these substitution elasticities are approximately 1 so that the cost shares of feed ingredients are very stable and change little in response to relative price changes. The exception is the substitution elasticity for forages in beef cattle, which is elastic. Thus, as drought increases, the price of concentrates allows for the replacement of forages enough to reduce the cost share for forages in beef cattle rations.

\section{Shocks for Crops and Livestock in 2011 and 2012}

Livestock and crop drought effects are calculated by comparing forecasts from the spring of 2011 before the drought began with actual outcomes. Exogenous shocks to national crop production are introduced in the harvest quarter and function as shifts in supply curves within the model. Table 2 lists the exogenous quarterly percentage change shocks administered for each crop and livestock sector. Each integrated sector adjusts after the shocks are administered according 
Table 2. Quarterly Percentage Change Shocks by Commodity

\begin{tabular}{|c|c|c|c|c|c|c|c|c|c|c|c|}
\hline Year & Quarter & $\begin{array}{l}\text { Winter } \\
\text { Wheat }\end{array}$ & $\begin{array}{l}\text { Spring } \\
\text { Wheat }\end{array}$ & $\begin{array}{l}\text { Winter } \\
\text { Coarse } \\
\text { Grains }\end{array}$ & $\begin{array}{l}\text { Spring } \\
\text { Coarse } \\
\text { Grains }\end{array}$ & Rice & Soy-beans & $\begin{array}{l}\text { Winter } \\
\text { Forage }\end{array}$ & $\begin{array}{l}\text { Spring } \\
\text { Forage }\end{array}$ & $\begin{array}{l}\text { Finished } \\
\text { Beef } \\
\text { Cattle }\end{array}$ & $\begin{array}{l}\text { Back-ground } \\
\text { Beef } \\
\text { Cattle }\end{array}$ \\
\hline \multirow[t]{4}{*}{2011} & 1 & 0 & 0 & 0 & 0 & 0 & 0 & 0 & 0 & 0 & 0 \\
\hline & 2 & 5.2 & 0 & 0 & 0 & 0 & 0 & -5.6 & 0 & 5.1 & -4.9 \\
\hline & 3 & 0 & -20.4 & -0.6 & 0 & 0.5 & 0 & 0 & -5.6 & 4.2 & -3.1 \\
\hline & 4 & 0 & 0 & 0 & -7.0 & 0 & -4.4 & 0 & 0 & 2.9 & -0.7 \\
\hline \multirow{4}{*}{2012} & 1 & 0 & 0 & 0 & 0 & 0 & 0 & 0 & 0 & -0.1 & -0.6 \\
\hline & 2 & -1.1 & 0 & 0 & 0 & 0 & 0 & -14.8 & 0 & 5.3 & -6.5 \\
\hline & 3 & 0 & 21.7 & -1.2 & 0 & 3.1 & 0 & 0 & -14.8 & 2.4 & -2.4 \\
\hline & 4 & 0 & 0 & 0 & -25.7 & 0 & -9.8 & 0 & 0 & 3.2 & -1.3 \\
\hline
\end{tabular}

Note: Exogenous percentage change shocks to national crop production for each sector are introduced in the harvest quarter. Shocks are based on the differences between yields in the World Agricultural Supply and Demand Estimates report (USDA-WAOB, 2013) issued prior to crop years 2011 and 2012 (May) and yields given in the January reports after crops have been harvested to capture the differences between the anticipated and realized yields. 
to the market-clearing conditions that dictate how producers and consumers adjust to changes in prices and quantities, which is described further in the "Results" section. Shocks are based on the differences between yields in the World Agricultural Supply and Demand Estimates (WASDE) report issued prior to crop years 2011 and 2012 (May) and yields given in the January reports after crops were harvested (USDA-WAOB, 2013). The intention is to capture the difference between the anticipated yield and the realized yield. Average per acre yield is used as the metric for drought effects instead of production because yield is more strongly affected by drought (Peel, 2013a). The WASDE report released before the crop year uses historical trend yields, whereas the values in the WASDE report for area planted are the planting intentions for the coming crop year as reported by farmers. By using crop yields as the measure for drought effects, any forecast error for yields is embedded in the calculated reductions.

Considerable differences between trend and realized yields are found. The WASDE report indicates that the 2011 yield for winter wheat was $5.2 \%$ greater than the trend for 2010. Winter wheat harvested in the summer of 2011 was planted in the fall of 2010 and had matured considerably prior to the damaging impact of the 2011 drought. Winter wheat yield in 2012 was $1.1 \%$ lower than trend. Spring wheat yield in the third quarter of 2011 was $20 \%$ lower than initial expectations based on trend but was more than $21 \%$ higher in 2012 . Although some areas experienced a decrease in yield as a result of drought conditions, there was rain in the spring wheat areas during 2012. Winter and spring coarse grains experienced yield decreases in both drought years. Winter coarse grain yield decreased by $1 \%$ in both 2011 and 2012, and spring grain yield-corn and sorghum-decreased by $7 \%$ in 2011 and by $26 \%$ in 2012. Soybean yield decreased by $4 \%$ and $10 \%$ in 2011 and 2012, respectively.

Changes in pasture and forage yields are derived from data provided by the Livestock Marketing Information Center (LMIC). Compared with trend yields, yield data reported by the LMIC for all hay types decreased by $6 \%$ in 2011 and by $15 \%$ in 2012. Drought effects on livestock slaughter in 2011 and 2012 are also based on LMIC data. ${ }^{1}$

The baseline database of the model relies on LMIC cattle slaughter and cattle inventory data from before the drought. The database in this analysis was constructed in early 2011 and is treated as the anticipated levels of cattle slaughter. Comparison of cattle slaughter for 2011 and 2012 in the database constructed prior to the drought and observed cattle slaughter in current data for 2011 and 2012 suggests unanticipated slaughter in all quarters (except the first quarter of 2012). Drought-induced slaughter of lighter cattle occurred in

1 Historical yield data for "All Hay" reported in short tons per acre by LMIC for 2011 and 2012 are compared with the historical national average trend yields for All Hay given the time frame 1974 to 2010 (LMIC, 2013). Deviations are based on the difference between trend and reported yields from LMIC for 2011 and 2012. 


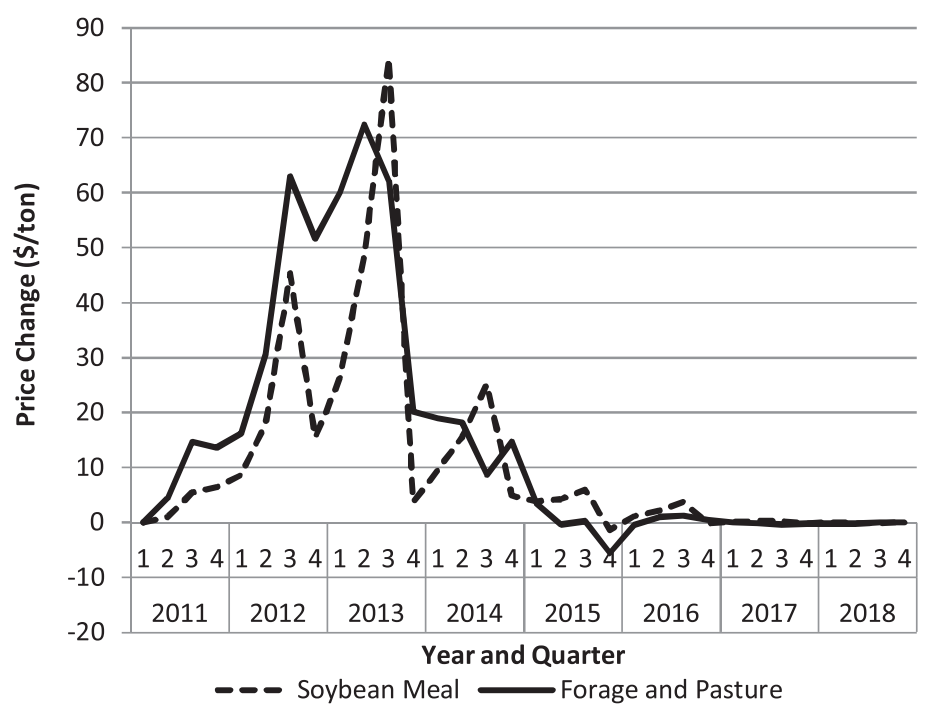

Figure 1. Change in Soybean Meal and Forage and Pasture Prices (magnitudes of crop price changes and trajectories between baseline and the model-calculated prices measured by dollars per U.S. short ton for each crop sector)

the second through fourth quarters of 2011. The increased slaughter in 2011 was largest in the second quarter and fell in the third and fourth quarters. The data from the first quarter of 2012 suggest that beef cattle producers held cattle in the hope of better crop and pasture conditions the following summer. As the drought did not improve in 2012, drought-induced slaughter increased again. Because the increase in cattle slaughter must come from lighter backgrounder cattle being slaughtered early, there are corresponding decreases in the supply of background beef cattle flowing into the next quarter. The percentage changes vary, but the total head decrease experienced by background cattle is the same as the increase in number of head for finished beef cattle.

\section{Results}

\subsection{Estimated Impacts of Drought on Prices}

The expected effects of the drought are driven by price changes resulting from the shocks that are administered to crops and livestock. Drought in 2011 and 2012 reduced crop production, which drives model-predicted increased commodity prices. Consequently, higher commodity prices within the model cause increased feed costs, which induce reductions in the livestock breeding inventory. The drought also induced greater cattle slaughter, which put downward pressure on cattle prices and accelerated the breeding herd reduction. The model-predicted magnitudes of crop price changes and trajectories are illustrated in Figures 1 


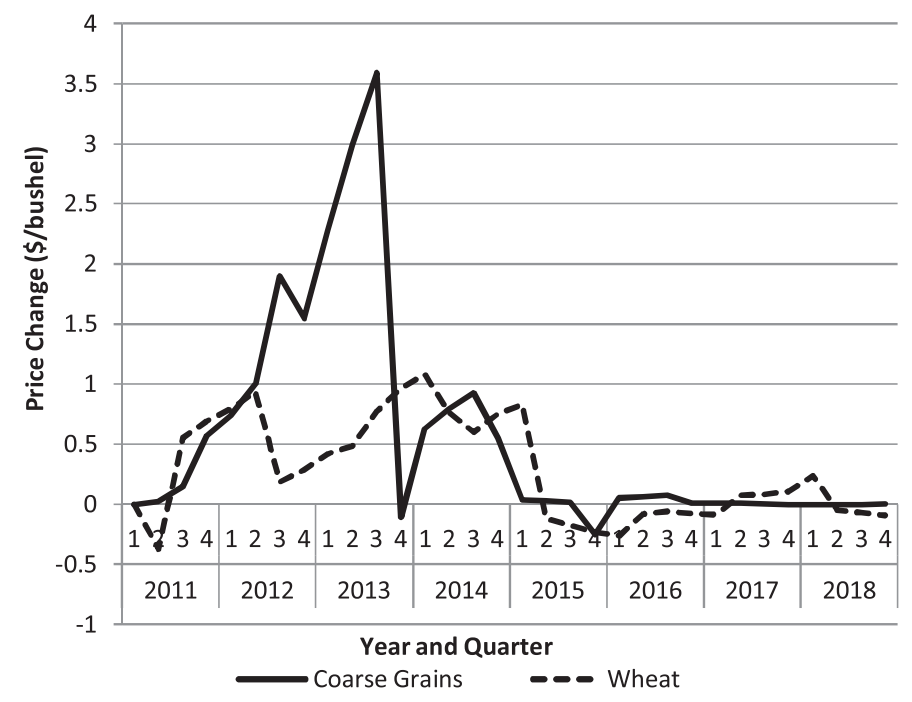

Figure 2. Change in Coarse Grains and Wheat Prices (magnitudes of crop price changes and trajectories between baseline and the model-calculated prices measured by dollars per bushel for each crop sector)

and 2. The initial impact of the drought was a reduction in observed forage and pasture supplies in the second quarter of 2011 (Table 2). The model-predicted forage price increased to $\$ 4.5 /$ ton above the baseline in the second quarter of 2011 and increased to nearly \$63/ton above the baseline in quarter 3 of 2012 (Figure 1). The largest difference between baseline and calculated forage prices was $\$ 72.4 /$ ton in the second quarter of 2013 . The price of forage and pasture is expected to return to the baseline in the fourth quarter of 2016. The largest differences between baseline and model-predicated soybean meal prices occurred in the third quarter of 2012 and 2013. Soybean meal prices are estimated to take 24 quarters (6 years) to return to the baseline.

As model-predicted forage and soybean meal prices rise, other crop prices increase as well. Initially, in quarters 2 and 3 of 2011, there are substitution effects in livestock feeding that cause sympathetic price rises for other feedstocks in the model. In addition, there are drought effects beginning in the third and fourth quarters of 2011 for coarse grains and other feedstocks. The modelpredicted price of coarse grains increases steadily until the third quarter of 2012, when the expected price is nearly $\$ 2 /$ bushel (bu) higher than the baseline (Figure 2). The increase in the coarse grain price in the fourth quarter of 2012 is relatively small because that is the harvest quarter. The model-predicted coarse grain price reaches a peak in the third quarter of 2013, a value of $\$ 3.6 /$ bu higher than the baseline. The price for coarse grain in the last quarter of 2013 drops substantially as the 2013 harvest occurs. Model-predicted price increases during 2014 are expected to cause livestock producers to continue to ration coarse grain 
use. Coarse grain prices are expected to return to levels near the baseline in the fourth quarter of 2016.

The expected changes in the wheat price are muted, relative to those for the other crops (Figure 2). This is attributable to the observed winter wheat yield increase that occurred in the second quarter of 2011 and the spring wheat yield increase that occurred in the third quarter of 2012. The largest changes between baseline and estimated wheat prices occur in the fourth quarter of 2013 and the first quarter of 2014, when the differences are approximately $\$ 1 / \mathrm{bu}$ each quarter. The model-predicted wheat price is expected to begin returning to the baseline during 2015 as do the prices of other crops. However, because the production cycle for winter wheat differs, prices are expected to fall slightly below the baseline during 2015 and into 2016 .

Changes in crop prices alter input costs for livestock. Forage and pasture, along with grains, are the crops with the largest impact on costs in the beef sector as they comprise the largest percentage of beef cattle feed. Drought also led to additional observed culling of breeding animals and further increased cattle slaughter. Increased slaughter affects cattle prices in the short run. Reduced cattle prices and higher feed costs reduce expected returns throughout the supply chain leading to a decrease in beef cattle inventory and a corresponding decrease in the supply of calves moving through the supply chain over time, which affects cattle prices in the long run, as indicated by model-predicted results.

The model-predicted changes in the finished steer price, ${ }^{2}$ compared with the baseline, vary over the drought years 2011-2012 (Figure 3). The model-predicted decline in the 2011 and 2012 steer price corresponds to the observed increase in slaughter cattle sent to market as a result of the drought. The second quarters of both 2011 and 2012 have increases in observed cattle slaughter, and the modelpredicted steer price is $\$ 13 /$ hundredweight (cwt) and $\$ 10 / \mathrm{cwt}$ below the baseline for the second quarters of 2011 and 2012, respectively. There is a jump in the model-predicted steer price to more than $\$ 14 / \mathrm{cwt}$ above the baseline in the third quarter of 2012, when cattle slaughter declines due to decreased herd sizes. As cattle inventories and the number of head slaughtered decrease, starting in 2013, the model-predicted steer price rises to nearly $\$ 16 / \mathrm{cwt}$ above the baseline in the third quarter of 2014. As inventories are rebuilt beginning in the fourth quarter of 2014, more calves are available to move through the market, cattle slaughter begins to increase, and the steer price returns toward the baseline.

Changes in the hog market are based on expected returns, which adjust in response to the changes in feed costs attributable to the crop shocks from drought. Forage and pasture are not major inputs in the hog sector, so expected returns primarily vary due to the changes in the prices of coarse grains and soybean meal. As model-predicted feed prices increase from 2011 to 2013,

2 The baseline and model-predicted steer prices are for the Nebraska Steer Price, following USDA historical reporting. 


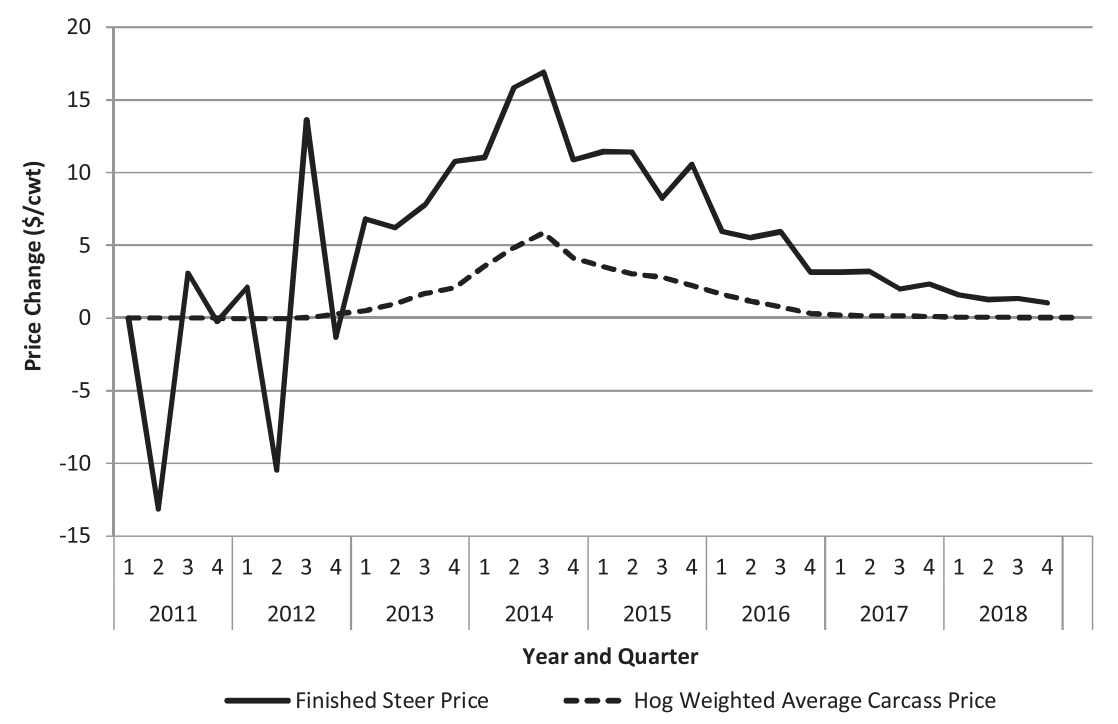

Figure 3. Changes in Finished Steer Price and Weighted Average Hog Carcass Price (magnitudes of finished steer and hog price changes and trajectories between baseline and the model-calculated prices measured by dollars per hundredweight)

hog breeding inventories decline steadily, and the quantity of hogs available for slaughter decreases as well. The weighted average carcass price for hogs increases to a maximum price of $\$ 5.84 / \mathrm{cwt}$ above the base in the second quarter of 2014 (Figure 3). As model-predicted hog slaughter decreases, the price for hog carcasses increases. Prices fall as slaughter numbers pick back up and approach the baseline for the remainder of the period of analysis.

Our results for price effects and livestock market adjustments are consistent with the findings of Paarlberg et al. (2008). Although those authors implement FMD-related negative shocks to production, their findings show that it takes beef and cattle sectors longer to return to baseline levels after the negative supply shocks are administered due to the longer production cycle relative to other sectors. In our work, livestock market disruptions for both cattle and hog sectors persist longer than the results presented by Paarlberg et al. (2008), given that we impose drought-related production shocks to both crops and livestock sectors over a 2-year time frame rather than the shorter duration of FMD-related supply shocks implemented by Paarlberg et al.

\subsection{Welfare Impacts of the Drought}

The estimated welfare impacts of the 2011 and 2012 drought compared with the baseline scenario vary by commodity and over time. The majority of the welfare loss due to the drought is shared primarily by livestock producers, processors, and consumers. Table 3 presents the welfare impacts by agricultural sector and 
Table 3. Change in Returns to Producers ${ }^{\mathrm{a}}$ and Consumer Surplus ${ }^{\mathrm{b}}$ from Drought in 2011 and 2012

\begin{tabular}{|c|c|c|c|c|c|c|c|c|c|}
\hline \multirow[b]{2}{*}{ Producers } & \multicolumn{9}{|c|}{ Million \$ } \\
\hline & 2011 & 2012 & 2013 & 2014 & 2015 & 2016 & 2017 & 2018 & Total \\
\hline Beef processors & 294.9 & -99.1 & -755.9 & $-1,318.3$ & $-1,071.1$ & -565.1 & -75.3 & -153.4 & $-3,743.3$ \\
\hline Beef cattle & $-1,560.8$ & $-4,629$ & $-4,769$ & 720.8 & $2,306.8$ & $1,061.5$ & 639.6 & 324.23 & $-5,905.87$ \\
\hline Pork processors & -4.3 & -42.9 & -188.3 & -297.8 & -144.4 & -36.4 & -7.1 & -1.7 & -722.9 \\
\hline Pork producers & -159 & -978.2 & $-1,597$ & 198.9 & 559.9 & 79.6 & 24.1 & 9.3 & $-1,862.4$ \\
\hline Milk and dairy & -111.9 & $-2,897.9$ & $-6,612.3$ & $-1,273.4$ & -153 & -174 & -67 & -28.8 & $-11,318.3$ \\
\hline Lamb processors & 0 & -0.9 & -2.7 & -3.6 & -1.4 & 0.4 & 1.2 & 1.3 & -5.7 \\
\hline Lamb and sheep & -5.8 & -13 & -11.7 & 7.6 & 11.2 & 5.4 & 3.1 & 1.6 & -1.6 \\
\hline Poultry meat & -99.9 & -490.6 & -697.8 & -139.1 & 33.5 & -61.2 & 2 & 1.2 & $-1,451.9$ \\
\hline Eggs & -34.7 & -310 & -512.6 & -130.1 & -5.6 & -8.1 & -0.8 & 0.2 & $-1,001.7$ \\
\hline Forage & -754.3 & $4,417.4$ & $26,083.5$ & $7,013.5$ & -210.5 & 338.4 & -74.5 & -57.9 & $36,755.6$ \\
\hline Coarse grains & $-2,672.3$ & $-3,310.3$ & $17,092.1$ & $7,826.1$ & -729.4 & 539.7 & 25.2 & -13.1 & 18,758 \\
\hline Soybeans & $-1,229.7$ & $-1,311.4$ & $3,379.5$ & $2,160.5$ & $1,250.7$ & 489 & 65.9 & 2.6 & $4,807.1$ \\
\hline Wheat & -754.7 & 936.6 & $1,285.7$ & 1,439 & 65.8 & -229 & 92.2 & 0.8 & $2,836.4$ \\
\hline Rice & 2.9 & 13.5 & 38 & 34.9 & 17.9 & 0.2 & 1.5 & -0.5 & 108.4 \\
\hline Soybean meal & -57.2 & -159.7 & -250.2 & -193.8 & -145 & -29.4 & -3.5 & -1.1 & -839.9 \\
\hline Land rent & 0 & $4,685.5$ & $18,084.4$ & $11,964.1$ & $5,893.3$ & 0.1 & 122 & 0 & $40,749.4$ \\
\hline $\begin{array}{l}\text { Total returns to producers } \\
\text { Consumers }\end{array}$ & $-7,146.8$ & $-4,190$ & $50,565.7$ & $28,009.3$ & $7,678.7$ & $1,411.1$ & 748.6 & 84.73 & $77,161.33$ \\
\hline Consumer surplus & $-5,398.9$ & $-29,165.1$ & $-49,287.2$ & $-20,867.1$ & $-2,801.1$ & $-2,234.5$ & -824.8 & -315.7 & $-110,894$ \\
\hline
\end{tabular}

aThe welfare impacts by agricultural sector and by year are measured by the change in returns to management and capital relative to the baseline.

${ }^{b}$ Estimates of the drought-induced loss in consumer surplus by year, relative to the baseline, are measured in millions of U.S. dollars. 
by year. For this analysis, producer welfare is measured by the change in returns to management and capital relative to the baseline.

The magnitude and timing of model-predicted welfare losses and gains by sector depend on several factors. Beef processors, for example, benefit from lower model-predicted steer prices in the first year of the drought. The reduction in steer price is greater than the reduction in meat price, thereby increasing margins and resulting in a gain of $\$ 295$ million in 2011 . In subsequent years, beef processors experience a loss in welfare compared with the baseline due to a reduction in the number of cattle slaughtered and higher live animal prices. The greatest loss to processors occurs 2 years after the end of the drought. By contrast, beef cattle producers are hit the hardest in the first 3 years of the drought. These annual losses relative to the baseline are a combination of higher model-predicted feed costs and lower steer prices due to an increase in observed drought-induced culls during that time period. Beginning in 2014, the change in beef producer welfare is positive because model-predicted steer prices are increasing and feed costs are beginning to decrease. However, the overall welfare impact for cattle producers compared with the baseline is a loss of $\$ 5.9$ billion over the 8 -year period of analysis. In this case, the declines in the early years clearly dominate the gains in later years.

The welfare impact of the drought on pork processors and hog farmers is slightly different than the beef sector. Hog farmers experience a loss in returns, relative to the baseline, over the first 3 years due to higher model-predicted feed costs. Hog producers respond over this time period by reducing the breeding herd, which results in fewer hogs marketed and an increase in hog prices beginning in 2014. The change in pork processors' returns, relative to the baseline, is negative over the entire 8 years. Decreases in returns are due to a contraction of hogs available for slaughter. The losses in the first few years are small but accelerate into 2014 as the breeding herd contracts before starting to recover. The poultry and egg sectors follow a similar pattern compared with hog producers; however, these sectors can adjust to higher feed costs at a faster rate. Paarlberg et al. (2008) similarly show negative welfare changes for livestock sectors given their analysis.

The model predicts that the dairy and milk sector experiences substantial welfare declines relative to the baseline due to drought. Milk production and dairy product processing are combined into one agricultural activity in the model. With an estimated decline in welfare of $\$ 11.3$ billion relative to the baseline over 8 years, the magnitude of annual losses is driven by the timing of high forage and grain prices. These model-predicted input price changes over time are clearly seen in Figures 1 and 2.

The national-level welfare impacts of the drought on crop producers are very different compared with livestock producers and processors. In general, the cropping sectors experience a net welfare gain relative to the baseline. Despite decreases in observed yields and production related to the drought, the gains 
Table 4. Decomposition of Changes in Crop Producer Welfare from Drought in 2011 and 2012

\begin{tabular}{llcr}
\hline \hline \multirow{2}{*}{ Forage } & \multicolumn{2}{c}{ Decomposition of Changes in Crop Producer Welfare ${ }^{\mathrm{a}}$ (million \$) } \\
\cline { 2 - 4 } & & 2011 & \multicolumn{2}{c}{2012} \\
\cline { 2 - 4 } Coarse grains & Change in returns on sales & $2,461.7$ & $13,267.8$ \\
& Value of lost crop & $-3,216$ & $-8,850.4$ \\
Soybeans & Change in returns on sales & $2,402.7$ & $14,068.4$ \\
\multirow{2}{*}{ Wheat } & Value of lost crop & $-5,075$ & $-17,378.7$ \\
& Change in returns on sales & 371.7 & $1,975.2$ \\
\multirow{2}{*}{ Rice } & Value of lost crop & $-1,601.4$ & $-3,286.6$ \\
& Change in returns on sales & 493.6 & $1,048.3$ \\
& Value of lost crop & $-1,248.3$ & -111.7 \\
\hline \hline
\end{tabular}

${ }^{a}$ Changes in the total returns to crop producers in 2011 and 2012 are composed of changes in returns on sales as well as the value of the crop loss due to drought, which are reported by crop type and year.

in returns generated by price increases for several crops outweigh the losses in production over the 8-year period of analysis.

It should be noted that changes in the total returns to crop producers in 2011 and 2012 are composed of changes in returns on sales as well as the value of the crop loss due to drought. These values are reported by crop type and year in Table 4. For example, forage in 2011 had an estimated drought loss of $\$ 3.2$ billion compared with an increase in the value of sales of $\$ 2.5$ billion. For forage producers, this corresponds to a national welfare decrease of $\$ 754$ million, relative to the baseline in 2011. In contrast, the drought impacts are different for the more extensive drought in 2012. National crop losses are estimated at $\$ 8.8$ billion, but the value of sales increased by $\$ 13.3$ billion with a net positive impact of $\$ 4.4$ billion. Those producers who had forage available benefited from the large price increase. Similar patterns are observed for most program crops over the first 2 years, with the exception of rice. Beyond the shocks of 2011 and 2012, returns to forage, coarse grains, and soybean producers peak in 2013 and remain relatively high through 2014, whereas returns to wheat are highest in 2014. The largest gains in producer welfare over the 8-year period occur in the forage and coarse grains sectors, which reach an annual maximum of $\$ 26.1$ billion and $\$ 17.1$ billion above the baseline, respectively. The high values for these primary feed inputs are driven primarily by price increases resulting from stocks being depleted over the drought years of 2011 and 2012.

Given the estimated net gains to most crop producers over the 8-year period of analysis, land rents are also expected to increase over time compared with the baseline. The changes in returns to land rent are calculated at the beginning of each calendar year based on the previous year's crop returns. This differencing 
process results in an increase in land rent over time that follows the change in returns for the majority of crops. Land rent is estimated to increase $\$ 40.7$ billion over 8 years.

Consumers also share the burden of the drought with agricultural producers, and it is evident that consumers will be worse off as a result of the drought. Consumer surplus is a measure of economic welfare and indicates the difference between the price consumers would be willing to pay and the market price they actually pay for each unit consumed. Table 3 provides estimates of the loss in consumer surplus by year, which captures the monetary value between what consumers were paying for agricultural products before the drought compared with the model-predicted price increases caused by drought. There is a loss in consumer surplus for the entire 8-year time frame. Surplus to consumers begins to decline in 2011 as prices for consumer goods rise and reaches its lowest point in 2013, when surplus to consumers is expected to be more than $\$ 49$ billion lower than the baseline level for that year. Losses to consumers begin to mitigate after 2013, yet remain below the base. The total expected welfare loss to consumers during the period 2011-2018 is nearly $\$ 111$ billion. In this case, consumers are expected to bear the cost of the 2012 and 2013 drought for several years beyond the actual drought.

\subsection{Potential Economic Impacts of Continued Drought}

One of the key contributions of this study is the ability to consider the effects of drought while taking into account the long-term dynamics of crop and livestock production sectors, which allows for the inclusion of drought shocks that persist over multiple years. This contribution is noteworthy, especially given the evidence that consecutive, multiyear droughts are more detrimental than short-term weather shocks, or one-off droughts (Ranjan, 2013). To assess the potential long-term impacts of continued drought in 2013, shocks to crop yields for an assumed drought are estimated from state yields and the U.S. Drought Monitor (The National Drought Mitigation Center, 2013). Data from the spring 2013 U.S. Drought Monitor indicate continued drought for the central and southern plains states. Therefore, the deviation of 2012 crop yields, as reported by the National Agricultural Statistics Service (NASS), compared with the long-run trend yield is used to determine the national production shocks to crop sectors for 2013 (USDA-NASS, 2013). Although continued drought may intensify beef cattle herd reductions, this study considers only estimated changes in crop production to assess potential continued drought impacts (Peel, 2013b). The estimates for continued drought in 2013 result in an assumed 5\% decrease in winter wheat yield in the second quarter; a 3\% decrease in spring coarse grains and a $5 \%$ decrease in soybean yield, both in the fourth quarter; and a $6 \%$ decrease to winter and spring forage in the second and third quarters of 2013, respectively. 


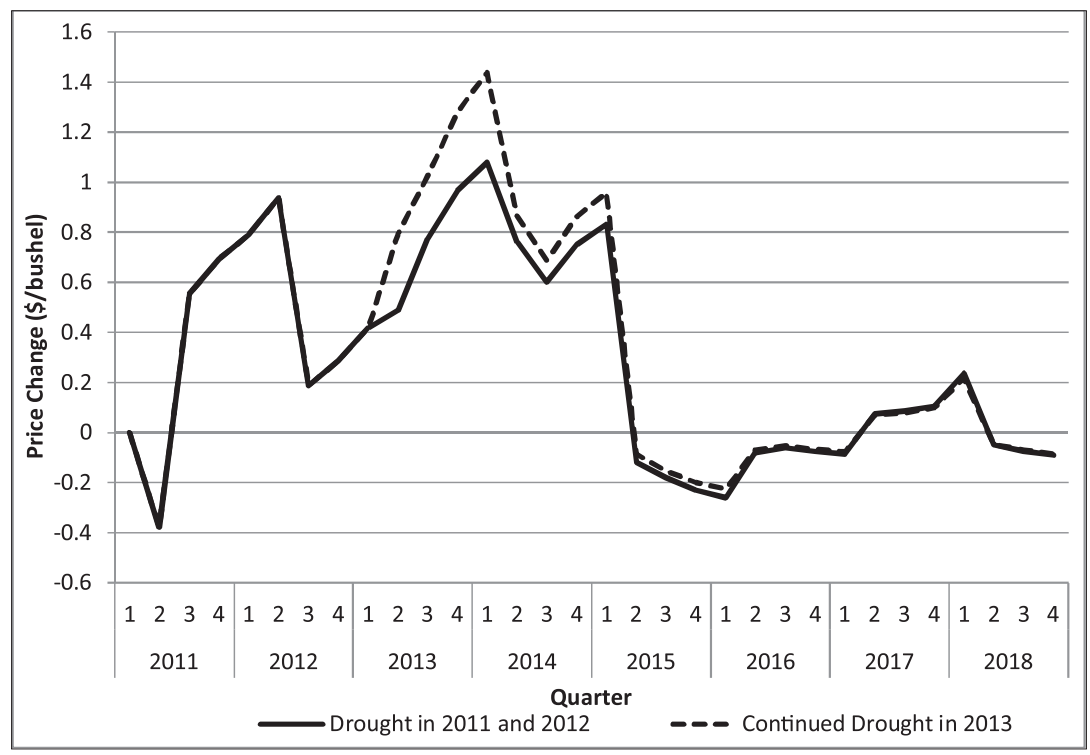

Figure 4. Comparison of Change in Wheat Price with Continued Drought in 2013 (magnitudes of crop price changes and trajectories between baseline and the model-calculated prices measured by dollars per bushel for the wheat sector for a first scenario when there is drought in 2011 and 2012, and for a second scenario when the drought continues in 2013)

Figures 4 through 6 illustrate the difference between prices for key changes in crop and livestock sectors for normal weather conditions resuming in 2013 versus continued drought in 2013. Both the 2-year and 3-year drought scenarios are compared with baseline levels. The overall impact of continued drought into 2013 results in an amplification of the price effects in each market segment and extends the time it takes to return toward the baseline. The largest difference between drought scenarios occurs in the wheat market because the dry conditions in 2013 are in critical wheat production regions. For wheat, the difference between the 3-year drought and the 2-year drought is largest from the first quarter of 2013 through the second quarter of 2015 (Figure 4). The average difference between the 3-year and 2-year drought scenarios for wheat in this time frame is $\$ 0.21 / \mathrm{bu}$, and the peak price difference, $\$ 1.44 / \mathrm{bu}$ above the baseline, occurs in the first quarter of 2014 . This value is $\$ 0.36 /$ bu higher than when drought is assumed to have ended in 2012. Although wheat is not a key feed input for livestock production, its model-predicted price increase affects consumers. The differences between the 3-year and 2-year drought scenarios for coarse grains and forage are muted, relative to the differences in wheat. Changes in coarse grain prices are not reported here, and the largest difference between drought scenarios for forage and pasture prices occurs between the second quarter of 


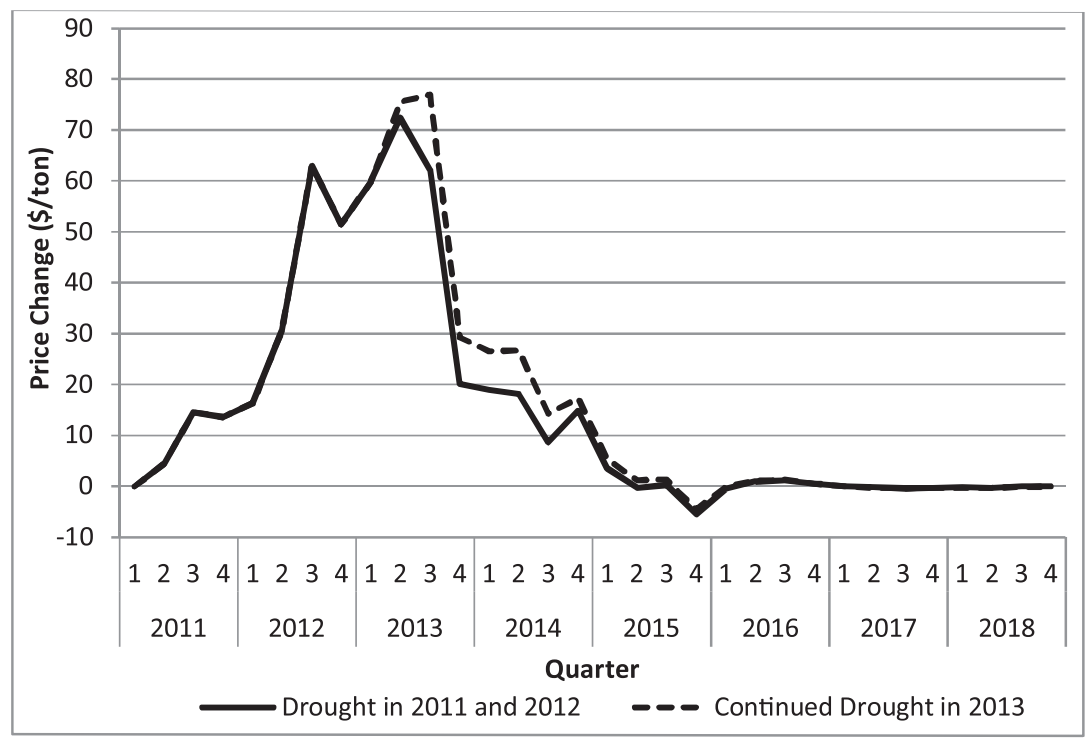

Figure 5. Comparison of Change in Pasture and Forage Price with 2013 Drought (magnitudes of crop price changes and trajectories between baseline and the model-calculated prices measured by dollars per U.S. short ton for the pasture and forage sector for a first scenario when there is drought in 2011 and 2012, and for a second scenario when the drought continues in 2013)

2013 and the fourth quarter of 2015, when the price under a 3-year drought scenario is an average of $\$ 5.17 /$ ton higher than if drought does not continue in 2013 (Figure 5).

Continued drought in 2013 causes an increase in the model-predicated steer price beginning in the second quarter of 2014 (Figure 6). The price remains higher for steers under the 3-year drought scenario. As expected, continued drought causes additional herd size reductions and further tightening of cattle supplies through the marketing channel. Cattle slaughter is an average of 28,000 head lower under the 3-year drought scenario versus the 2-year drought scenario beginning in the second quarter of 2014 through the remainder of the period of analysis. The decrease in slaughter cattle supplies causes further increases in steer prices relative to the case where drought does not continue in 2013 as illustrated in Figure 6.

\section{Conclusions}

Key contributions of this work include the modeling of the long-run time dynamics of U.S. livestock products, livestock, and crops to understand the national impacts of the 2011 and 2012 drought on the U.S. agricultural economy, as well as the potential effects of an extended drought into 2013. Although several 


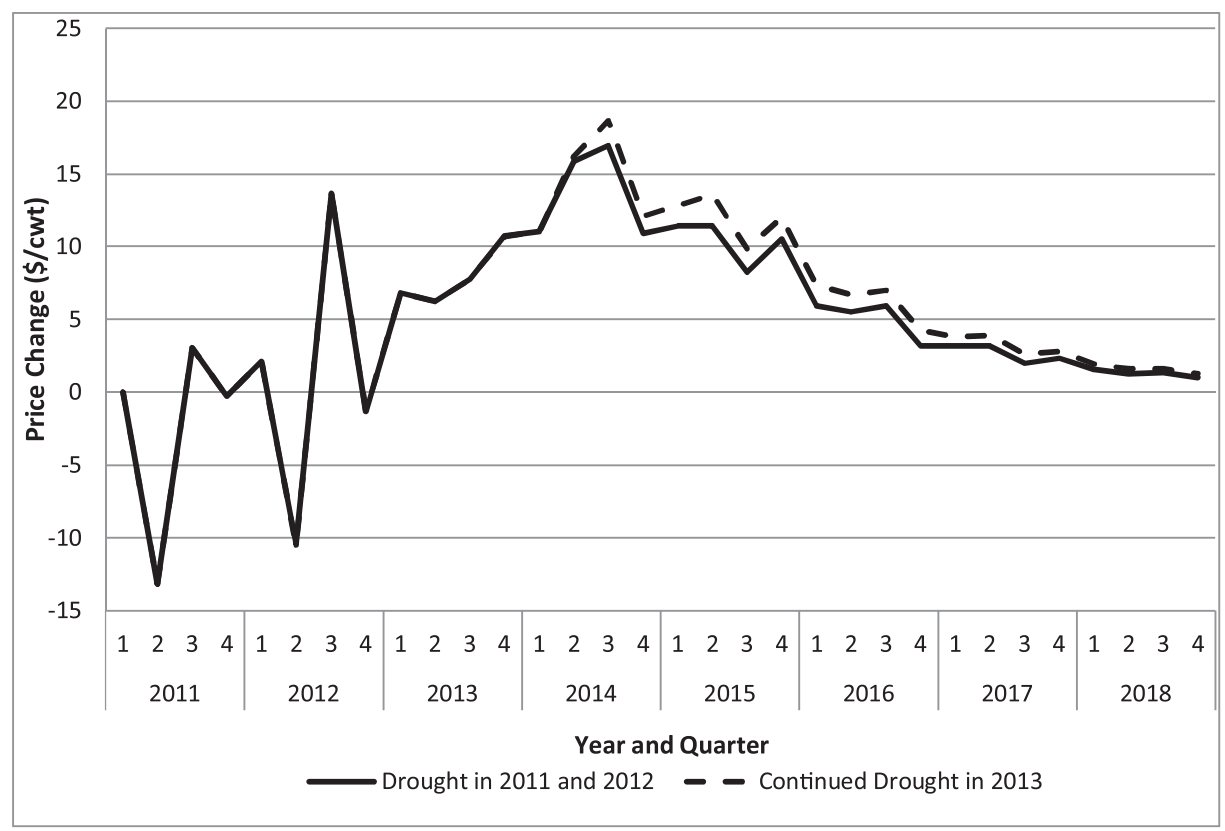

Figure 6. Comparison of Change in Finished Steer Price with Continued Drought in 2013 (magnitudes of crop price changes and trajectories between baseline and the model-calculated prices measured by dollars per hundredweight for steers for a first scenario when there is drought in 2011 and 2012, and for a second scenario when the drought continues in 2013)

studies have assessed the short-term impacts of drought on U.S. agriculture, this research shows that much of the drought effects occur in subsequent years following the actual drought itself, highlighting the need for longer-term, dynamic analysis. Results show short-term drought effects including increases in crop and forage prices in tandem with decreased live cattle prices resulting from increases in slaughter due to drought-induced beef cattle herd liquidation. Long-run drought impacts result in model-predicted crop price increases that cause livestock inventory reductions due to reduced expected future returns. As herd sizes decrease, there are fewer animals moving through the U.S. meat supply chain, which leads to decreases in animal slaughter and increased livestock prices in the long run.

Although U.S. agricultural commodities are becoming more tolerant to drought conditions over time, the economic losses resulting from the drought on a national level are substantial (Yu and Babcock, 2010). Drought-induced welfare losses are shared by livestock producers, processors, and consumers. In the long run, meat processors experience a loss in welfare compared with the baseline due to reductions in slaughter and higher livestock prices. Livestock producers suffer from escalating feed costs and drought-induced increases in 
animal slaughter that decrease U.S. livestock inventories overall. The poultry and egg sectors suffer from higher feed costs. The dairy and milk sector is hard hit by drought, also a result primarily driven by relatively high feed costs. Unlike livestock producers and processors, crop producers experience a net welfare gain relative to the baseline, resulting from increases in prices for several crops that outweigh yield and production losses due to drought.

Longer-term market adjustments cause a significant decrease in consumer surplus over the 8-year period of analysis, while prolonged drought in 2013 amplifies the model-predicted price changes and extends the time needed for key variables to return to baseline levels. This study is of particular importance because it assesses the long-term impacts of the 2011 and 2012 drought on the U.S. agricultural economy.

\section{References}

Anderson, D.P., J.M. Welch, and J. Robinson. “Agricultural Impacts of Texas's Driest Year on Record.” AAEA Choices 27(March 2012):1-3.

Banerjee, O., R. Bark, J. Connor, and N.D. Crossman. “An Ecosystem Services Approach to Estimating Economic Losses Associated with Drought." Ecological Economics 91(2013):19-27.

Bauman, A., C. Goemans, J. Pritchett, and D.T. McFadden. "Estimating the Economic and Social Impacts from the Drought in Southern Colorado." Journal of Contemporary Water Research \& Education 151(August 2013):61-69.

Boubacar, I. "The Effects of Drought on Crop Yields and Yield Variability: An Economic Assessment." International Journal of Economics and Finance 4(2012):51-60.

Brester, G.W., and T.C. Schroeder. "The Impacts of Brand and Generic Advertising on Meat Demand." American Journal of Agricultural Economics 77(1995):969-79.

Dhoubhadel, S.P., A.M. Azzam, and M.C. Stockton. "The Impact of Biofuels Policy and Drought on the U.S. Grain and Livestock Markets.” Journal of Agricultural and Applied Economics 47,1(February 2015):77-103.

Ding, Y., M.J. Hayes, and M. Widhalm. "Measuring Economic Impacts of Drought: A Review and Discussion." Disaster Prevention and Management: An International Journal 20(April 2011):434-46.

Dorfman, J.H., and W.D. Lastrapes. "The Dynamic Responses of Crop and Livestock Prices to Money-Supply Shocks: A Bayesian Analysis Using Long-Run Identifying Restrictions.” American Journal of Agricultural Economics 78(March 1996):530-41.

Eales, J.S., and L.J. Unnevehr. "Demand for Beef and Chicken Products: Separability and Structural Change." American Journal of Agricultural Economics 70(1988): $521-32$.

Gramig, B.M., and R.D. Horan. "Jointly Determined Livestock Disease Dynamics and Decentralised Economic Behaviour." Australian Journal of Agricultural and Resource Economics 55(July 2011):393-410.

Guidry, K.M., and J.R. Pruitt. "Damages to Louisiana Agriculture from Natural Disasters." AAEA Choices 27(March 2012):1-6.

Horridge, M., J. Madden, and G. Wittwer. "The Impact of the 2002-2003 Drought on Australia.” Journal of Policy Modeling 27(2005):285-308. 
Jia, R. "Weather Shocks, Sweet Potatoes and Peasant Revolts in Historical China." Economic Journal 124(March 2014):92-118.

Julca, A. "Natural Disasters with Un-Natural Effects: Why?" Journal of Economic Issues 46 (June 2012):499-510.

Kusunose, Y., and T.J. Lybbert. "Coping with Drought by Adjusting Land Tenancy Contracts: A Model and Evidence from Rural Morocco." World Development 61(September 2014):114-26.

Lawson, D., and I. Kasirye. "How the Extreme Poor Cope with Crises: Understanding the Role of Assets and Consumption." Journal of International Development 25 (November 2013):1129-43.

Livestock Marketing Information Center (LMIC). Internet site: http://www.lmic.info (Accessed 2013).

Maystadt, J.-F., and O. Ecker. "Extreme Weather and Civil War: Does Drought Fuel Conflict in Somalia through Livestock Price Shocks?" American Journal of Agricultural Economics 96(2014):1157-82.

Mwakaje, A.G. "The Impact of Climate Change and Variability on Agro-Pastoralists' Economy in Tanzania." Environmental Economics 1(2013):30-38.

The National Drought Mitigation Center. "United States Drought Monitor.” Internet site: http://droughtmonitor.unl.edu (Accessed 2013).

Paarlberg, P.L., A.H. Seitzinger, J.G. Lee, and K.H. Mathews, Jr. Economic Impacts of Foreign Animal Disease. Washington, DC: U.S. Department of Agriculture, Economic Research Service, Economic Research Report No. 57, 2008.

Peel, D.S. "Impacts of Drought and Regional Change on Hay Production." Cow/Calf Corner, Stillwater, OK: Oklahoma State University Extension, April 15, $2013 \mathrm{a}$. - "More Beef Herd Liquidation in 2013?” Cow/Calf Corner, Stillwater, OK: Oklahoma State University Extension, April 8, 2013 b.

Ranjan, R. "Mathematical Modeling of Drought Resilience in Agriculture." Natural Resource Modeling 26(May 2013):237-58.

Seale, J.L, Jr., A. Regmi, and J.A. Bernstein. International Evidence on Food Consumption Patterns. Washington, DC: Economic Research Service, Technical Bulletin No. TB-1904, October 2003.

Tonsor, G.T., and T.L. Marsh. "Comparing Heterogeneous Consumption in U.S. and Japanese Meat and Fish Demand." Agricultural Economics 37(July 2007): 81-91.

Tonsor, G., J. Mintert, and T. Schroeder. U.S. Beef Demand Drivers and Enhancement Opportunities. Manhattan, KS: Kansas State University Agricultural Experiment Station and Cooperative Extension Service, June 2009.

U.S. Department of Agriculture, Economic Research Service (USDA-ERS). "Food Demand Analysis: Ordinary Food Demand System, Table 1-Price Elasticity Estimates.” Washington, DC: USDA-ERS. Internet site: http://www.ers.usda.gov/topics/food-choices-health/ food-consumption-demand/food-demand-analysis/table-1.aspx (Accessed June 5, 2012).

U.S. Department of Agriculture, National Agricultural Statistics Service (USDA-NASS). "Statistics by State." Internet site: http://www.nass.usda.gov/Statistics_by_State/ (Accessed April 14, 2013).

U.S. Department of Agriculture, World Agricultural Outlook Board (USDA-WAOB). World Agricultural Supply and Demand Estimates (WASDE). Internet site: http://www.usda. gov/oce/commodity/wasde/index.htm (Accessed March 10, 2013). 
Verner, D., and C. Breisinger. Economics of Climate Change in the Arab World: Case Studies from the Syrian Arab Republic, Tunisia, and the Republic of Yemen. Washington, DC: International Bank for Reconstruction and Development/The World Bank, A World Bank Study 76368, 2013.

Wallander, S., M. Aillery, D. Hellerstein, and M. Hand. The Role of Conservation Programs in Drought Risk Adaptation. Washington, DC: U.S. Department of Agriculture, Economic Research Service, Economic Research Report No. 148, 2013.

Watkins, K.B. “The 2010 and 2011 Arkansas Drought Experience.” AAEA Choices 27(March 2012):1-7.

Westcott, P., and M. Jewison. Weather Effects on Expected Corn and Soybean Yields. Washington DC: Economic Research Service, Report No. FDS-13g-01, July 2013. Internet site: http://www.usda.gov/oce/forum/presentations/Westcott_Jewison.pdf

Yu, T., and B. Babcock. "Are US Corn and Soybeans Becoming More Drought Tolerant?" American Journal of Agricultural Economics 21(October 2010):1310-1323. 